\title{
Resenha de "A natureza primordial"
}

DOI: 10.12957/ek.2021.54246

\author{
Renato dos Santos ${ }^{1}$ \\ Pontifícia Universidade Católica do Paraná \\ renatodossantos1@hotmail.com \\ https://orcid.org/0000-0002-1402-7162
}

\section{Resenha crítica e bibliográfica de:}

SILVA, C. A. F. A natureza primordial: Merleau-Ponty e o 'logos do mundo estético'. 2. ed. Cascavel, PR: Edunioeste, 2019.

Na sua segunda edição, o livro A natureza primordial: Merleau-Ponty e o 'logos do mundo estético', de Claudinei Aparecido de Freitas da Silva, brinda os leitores interessados na filosofia de Merleau-Ponty. É que, desta vez, o autor retomou sua primeira edição - já esgotada! -, alargando ainda mais a discussão do tema da Natureza na filosofia do filósofo francês. Refiro-me aos escritos póstumos de Merleau-Ponty, às notas de trabalho que o filósofo redigiu alguns anos antes de seu falecimento e, dentre estas notas, estava o tema da Natureza, que Merleau-Ponty, ao longo de toda sua obra, manifestou profundo interesse. É percebendo isso que Claudinei, com seu estilo filosófico que o seu leitor já conhece, ou seja, de forma clara e vertical dos conceitos, traça um fio condutor pela obra do filósofo francês, desde La structure $d u$ comportement (1942), até os últimos escritos. Nesta recensão, pontuarei algumas percepções de minha leitura do minucioso trabalho A natureza primordial.

Algumas questões, talvez, possam surgir quando se ouve a palavra "natureza", por exemplo: por que, em pleno século XXI, convém falar no tema da Natureza? Em especial na filosofia, por que a Natureza ainda pode ser uma questão filosófica? Quais

\footnotetext{
${ }^{1}$ Doutorando em Filosofia pela Pontifícia Universidade Católica do Paraná em regime de cotutela com a Universidade de Coimbra.
} 
implicações filosóficas este tema pode suscitar? Será que com todo o progresso da humanidade, principalmente no âmbito tecnológico, precisamos ainda pensar na Natureza? Estas e outras questões surgem quando indagamos qual o sentido que a noção de Natureza possui para além de uma concepção que lhe confere o plano da mera extensão, ou seja, de um objeto passível de manipulação, estratificação, quantificação, por parte do ser humano.

Esta concepção, na verdade, muito cara à ciência moderna e ao pensamento filosófico de caráter cartesiano, compreendeu, por muito tempo, a Natureza como um aglomerado de objetos justapostos que se relacionam por uma lógica causal. Neste âmbito, o sujeito é aquele que manipula estes objetos, e que toma a Natureza como possível se conhecer, bastando para isso apenas um método eficaz que conduza seu intelecto a fim de conhecer a verdade da Natureza.

É em contraste com este pano de fundo que o livro de Claudinei traz à baila a noção de Natureza, conforme concebida na filosofia de Merleau-Ponty, sob uma perspectiva não mais naturalista, mas "uma Natureza como espaço originário de transcendência, como solo, morada, ou ainda, como um horizonte no qual o homem, a animalidade, a cultura e a arte se entrelaçam carnalmente” (p. 13). Para sustentar esta tese, o livro é composto por quatro capítulos, além da conclusão, da introdução e uma nota pela ocasião à segunda edição e do prefácio de Marcos José Muller - outro grande pesquisador brasileiro da obra de Merleau-Ponty.

Já no primeiro capítulo, que leva o título de A gênese estrutural da natureza, pode-se notar a radicalidade do propósito do autor ao resgatar, conforme o pensamento de Merleau-Ponty, a Natureza em sua dimensão primordial, antes mesmo de nós a concebê-la por nosso pensamento reflexivo. Aliás, Claudinei é bem-sucedido em iniciar o capítulo retomando uma passagem de La structure du comportement, em que se expressa uma questão que fora muito cara ao filósofo francês, a tal ponto de estampar já na abertura do livro de 1942, a saber: "compreender as relações entre a consciência e a natureza - orgânica, psicológica ou mesmo social. Entende-se aqui por natureza uma multiplicidade de acontecimentos exteriores uns aos outros e ligados por relações de causalidade" (MERLEAU-PONTY, 1942, p. 1).

$\mathrm{Na}$ verdade, o que o filósofo propõe é trazer à tona uma outra perspectiva em torno da noção de Natureza, para além das noções clássicas que ficaram sedimentadas 
no ocidente por meio das filosofias humanistas e naturalistas. Estas filosofias comumente conceberam a Natureza como acessível em sua totalidade para o homem, este entendido como ser especial. É o homem que conhece a Natureza, é ele quem decifra e define seus objetivos. Ora, uma perspectiva humanista acredita que a Natureza é mero objeto para si, passível, portanto, de se fazer dela seja o que for. Penso aqui, por exemplo, nas grandes construções, como usinas de minérios que estratificam o máximo possível dos meios naturais para gerar lucro.

Forçar os limites da própria Natureza para conseguir extrair o máximo possível, como no caso da barragem de Brumadinho, em Minas Gerais, onde se pode constatar, ao vivo e a cores, as consequências de uma visão humanista em que entende a Natureza como mero objeto. Quando se compreende a Natureza como objeto se tem, na verdade, a tendência de negar a finitude. A Natureza é finita, ao menos no sentido de sua transformação de um estado a outro, e que ocorre pela própria contingência. No caso de Brumadinho, ao contrário, não foi algo da ordem da contingência, mas sim uma deflagração violenta por parte de um modo de pensar a Natureza como mero objeto.

Nesta direção, Merleau-Ponty - e Claudinei está atento para isso - busca pensar um estatuto ontológico para a Natureza, desvelando-a como carne, estofo primordial que não está fora de nós como objeto, mas dentro, enquanto instituição de nossa existência. Por isso a Natureza, a verdadeira Natureza de que fala Merleau-Ponty, só poderia ter este caráter de salvaguardar a dimensão do ser selvagem, do ser bruto enquanto logos primordial dos fenômenos, dentre eles os próprios fenômenos culturais. A partir do momento em que superamos a ideia de um início e de um fim, também as questões culturais ganham outra interpretação. É que se for verdade a perspectiva segundo a qual somos sujeitos inacabados, também é verdade que nossas perspectivas não podem ter um valor de absoluto, que a verdade não pode ser concebida como dogmática, mas aberta às participações de outras posições.

A intersubjetividade, por exemplo, ganha uma nova possibilidade de ser entendida a partir desta reabilitação ontológica da Natureza, ou seja, não mais a ideia de dois sujeitos frente a frente, mas como envolvimento, Ineinander carnal, como figura sobre fundo, ou ainda como unheimlich. Se a própria Natureza primordial funciona sob o signo do entrelaçamento carnal, nossa existência, pertencente a esta mesma Natureza, também segue a mesma lógica de promiscuidade, ou, para dizer noutras palavras, “a 
carne do corpo anuncia outra carne: a carne do mundo" (SILVA, 2019, p. 24). A carne do mundo é nossa carne, mais arcaica, arqueológica. Se experiencia em minha existência pessoal algo como um fundo misterioso, é porque este mistério é mais profundo, está ligado ao mistério da própria Natureza.

A noção de "mistério" abre margem para um profícuo diálogo com a psicanálise, como bem fizera Merleau-Ponty ao longo de sua obra. Conforme bem mostra Claudinei, o diálogo psicanalítico tem destaque no debate sobre o tema da Natureza, em especial para compreender o sentido arqueológico da existência humana. Em que sentido? A psicanálise nos ensina que nossos comportamentos não são decorrentes de uma racionalidade, de um cogito transparente para si mesmo. A dimensão inconsciente revela que nossa vida oficial não é absoluta, que há sempre um fundo anônimo que participa como outro lado. Isso nos permite pensar, por exemplo, que há uma presença de uma ausência que se dá de forma ativa em nossa vida, tal como a noção de Natureza estamos a tratar.

Talvez a melhor definição que esclareça o sentido da Natureza, de que propõe Merleau-Ponty, seja aquela passagem presente na introdução do curso sobre $A$ Natureza, e que Claudinei a usa como fio condutor em seu livro, a saber:

É Natureza o primordial, ou seja, o não-construído, o não-instituído; daí a ideia de uma eternidade da Natureza (eterno retorno), de uma solidez. A Natureza é um objeto enigmático, um objeto que não é inteiramente objeto; ele não está inteiramente diante de nós. É o nosso solo, não aquilo que está diante, mas o que nos sustenta (MERLEAU-PONTY, 1995, p. 4).

A Natureza, portanto, é um organismo vivo, ou para dizer como o filósofo, ela é a mãe, e nossa existência é carne de sua carne - "a carne do corpo anuncia a carne do mundo", ou seja, a carne da Natureza. Enquanto sujeitos, nós somente podemos reconhecer algo se este algo nos for familiar, ou seja, se nos for íntimo. Uma exterioridade íntima: aquilo que está em mim mas, ao mesmo tempo, está fora, no sentido de exceder-me. Assim parece ser a Natureza: ao mesmo tempo em que nos sustenta, não se deixa reduzir ao nosso desejo de apreendê-la completamente. Mantémse sempre inacabada, aliás, sua característica fundamental. A Natureza é não-toda acessível, sempre seu mistério nos convoca lhe indagar mais, ainda.

É este mistério fundamental que o desejo se inscreve, sempre recomeçando, satisfazendo parcialmente, pois precisa recomeçar, seguir a marcha, a reversibilidade da 
carne do corpo e do mundo. É nesta direção que A natureza primordial nos conduz: reaprender a ver o mundo com seus mistérios. O ser humano para tentar negar o mistério que lhe é íntimo - e com isso eu quero dizer negar aquilo que contém este mistério, seja a Natureza, meu semelhante ou até si mesmo (no caso do suicídio) -, tenta exterminar aquilo que o contém.

Nossa sociedade costuma exterminar aquilo que é misterioso, o estranho. É mais fácil exterminar do que compreender. É uma saída desesperada para o que não se tem domínio. Porém, esquece-se de que este estranho, este mistério, é íntimo. Por esta razão é que se faz pertinente o convite a revisitar nossa Natureza primordial, nossa arqueologia, e perceber que, na verdade, o dentro e o fora estão em quiasma um com o outro, restando então a tentativa de sairmos da lógica solipsista que assola o pensamento ocidental e adoece os sujeitos.

\section{Referências bibliográficas}

MERLEAU-PONTY, M. La structure du comportement. Paris: PUF, 1942.

MERLEAU-PONTY, M. La nature: Notes Cours du Collège de France. Paris: Seuil, 1995.

SILVA, C. A. F. A natureza primordial: Merleau-Ponty e o 'logos do mundo estético'. 2. ed. Cascavel, PR: Edunioeste, 2019.

Recebido em: 03/09/2020 | Aprovado em: 12/10/2020 